\title{
CFD modelling of traffic-related air pollutants around an urban street-canyon in Suzhou
}

\author{
F. Costabile, F. Wang, W. Hong, F. Liu \& I. Allegrini \\ ${ }^{I}$ Institute for Atmospheric Pollution, National Research Council, \\ Rome, Italy \\ ${ }^{2}$ Environmental Monitoring Center, Suzhou, P.R.China
}

\begin{abstract}
The wind flow field around urban street-building configurations has an important influence on the microscale pollutant dispersion from road traffic, affecting overall dilution and creating localized spatial variations of pollutant concentration. It is important to understand these small-scale effects not only for assessing personal exposure to pollutants in the vicinity of roads, but also because air quality in a city as a whole is assessed on the basis of data from a few urban monitoring sites. This paper reports some outcomes of a study aimed at exploring the transfer and diffusion characteristics of vehicular exhaust emissions and the constraints associated with significant monitoring locations such as street canyons, courtyards and enclosed spaces, and the conditions propitious to pollutant diffusion and air dispersion in urban areas. The wind field around a street-canyon in the city of Suzhou (China) has been modelled by using the Computational Fluid Dynamic technique. The results have been analysed to better understand the values of gaseous pollutants, meteorological parameters and traffic flows measured by means of automatic analyzers along the same street-canyon at two different heights. It has been found that the model correctly describes the vortex recirculation pattern around the building geometry studied and it is very useful in assessing the micro-scale pollution trends.
\end{abstract}

Keywords: street-canyon, Computational Fluid Dynamic, modelling, air pollution, traffic emission.

\section{Introduction}

The wind flow field around urban street-building configurations has an important influence on the microscale pollutant dispersion from road traffic, affecting 
overall dilution and creating localized spatial variations of pollutant concentration [1]. Classic examples of microscale dispersion effects in urban areas are those associated with street canyon, the common urban street-building geometry of a street bounded by buildings on both sides [2]. A vortex recirculation pattern is set-up, creating a small-scale spatial variation of concentration characterized by significant differences in concentration at street level between the lee- and wind- ward sides of the canyon. It is important to understand these small-scale effects not only for assessing personal exposure to pollutants in the vicinity of roads, but also because air quality in a city as a whole is assessed on the basis of data from a few urban monitoring sites.

In order to investigate this concern, researchers have conducted lots of studies mainly based upon three different approaches: field monitoring in street canyon [3], wind tunnel simulation [4], and computational fluid-dynamic (CFD) modelling [5]. The problem has also been faced up in China [6,7].

This paper reports some outcomes of a study aimed at exploring the transfer and diffusion characteristics of vehicular exhaust emissions and the constraints associated with significant monitoring locations such as street canyons, courtyards and enclosed spaces, and the conditions propitious to pollutant diffusion and air dispersion in urban areas [8]. The wind field around a streetcanyon in the city of Suzhou (China) has been modelled by using Computational Fluid Dynamic technique, while gaseous pollutants, meteorological parameters and traffic flows measured at two different heights during an intensive three days monitoring campaign. The results of CFD modelling and field measurements have been integrated to assess the trends of air pollutants.

\section{Experimental}

With an urban population of 2.07 million people, Suzhou is one of the China's most important coastal cities. The street-canyon studied in this paper is located in the middle of the city, near a small park, in Sanxiang road, a 50-meter wide eastwest oriented road with three lanes per direction, and a 4-meter large pavement lined by trees at both side. Into the monitoring area there are 5 buildings southward with a width/height $(\mathrm{W} / \mathrm{H})$ ratio of $1.8 \sim 3$, and 4 buildings northward with $\mathrm{W} / \mathrm{H}$ ratio of $3 \sim 3.5$. Considering it a typical open street-canyon lined by middle-low buildings with $\mathrm{W} / \mathrm{H}$ ratio greater than 1.8 , this location was selected, as the first case-site to conduct field monitoring and investigate the vertical distribution of traffic air pollution. A fixed monitoring station is located on the roof of the building at site A, sampling inlet is 13 meters high. A mobile unit was located into the yard at site B, sampling inlet 3 meters high (Fig.1).

Star-CD software package, version 3.20 has been used as computational fluid dynamic code.

The mass and momentum conservation equations (the Navier-Stokes equations) solved by STAR-CD for general incompressible and compressible fluid flows are, in Cartesian tensor notation: 


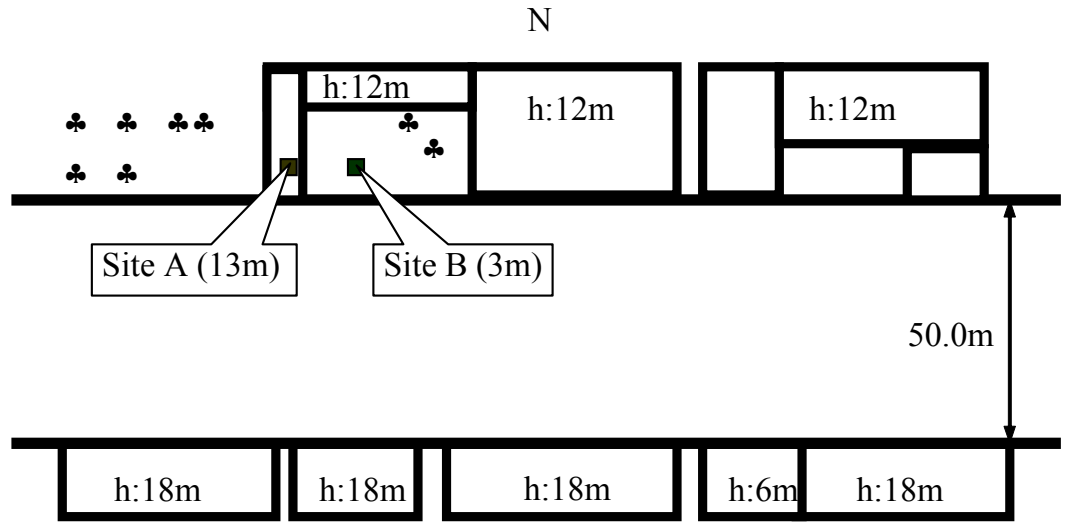

Figure 1: Geometry of the street-canyon with the indication of the two measurement points at site $\mathrm{A}$ and site $\mathrm{B}$.

$$
\begin{aligned}
& \frac{\partial \rho}{\partial t}+\frac{\partial}{\partial x_{j}}\left(\rho u_{j}\right)=s m \\
& \frac{\partial \rho u_{i}}{\partial t}+\frac{\partial}{\partial x_{j}}\left(\rho u_{j} u_{i}-\tau_{i j}\right)=-\frac{\partial p}{\partial x_{i}}+s_{i}
\end{aligned}
$$

where $\mathrm{t}=$ time; $\mathrm{x}_{\mathrm{i}}=$ Cartesian coordinate $(\mathrm{i}=1,2,3) ; \mathrm{u}_{\mathrm{i}}=$ absolute fluid velocity component in direction $\mathrm{x}_{\mathrm{i}} ; \mathrm{p}=$ piezometric pressure; $\rho=$ density; $\tau_{\mathrm{ij}}=$ stress tensor components; $\mathrm{s}_{\mathrm{m}}=$ mass source; $\mathrm{s}_{\mathrm{i}}=$ momentum source components.

For turbulent flows, as in this case, $\mathrm{u}_{\mathrm{i}}, \mathrm{p}$ and other dependant variables, including $\tau_{\mathrm{ij}}$, assume their ensemble averaged values (equivalent to time averages for steady-state situations) giving, for Newtonian fluids:

$$
\tau_{i j}=2 \mu s_{i j}-\frac{2}{3} \mu \frac{\partial u_{k}}{\partial x_{k}} \delta_{i j}-\bar{\rho} \overline{u_{i}^{\prime} u_{j}^{\prime}}
$$

where the $u$ ' are fluctuations about the ensemble average velocity and the overbar denotes the ensemble averaging process. The rightmost term in the above represents the additional Reynolds stresses due to turbulent motion. These are linked to the mean velocity field via the turbulence models. The well-known $\mathrm{k}-\varepsilon$ turbulence model has been used in this work, comprising transport equations for the turbulence kinetic energy $\mathrm{k}$ and its dissipation rate $\varepsilon$. In this model, $\mathrm{k}$ and $\varepsilon$ are chosen as typical turbulent velocity scale and length scale, respectively.

The success or failure of a fluid simulation depends not only on the code capabilities, but obviously also upon the input data, such as: geometry of the flow domain, fluid properties, boundary conditions, solution control parameters. For a simulation to have any chance of success, such information should be physically realistic and correctly presented to the analysis code. Consequently, for this work high accuracy and temporal resolution measurements were used to 
get the data. Three days of field monitoring were carried out, from June the $29^{\text {th }}$ to July the $1^{\text {st }}, 2005$. The pollutant concentration profiles of $\mathrm{NO}_{\mathrm{x}}, \mathrm{NO}_{2}, \mathrm{NO}$ were measured every 5 minutes by the fixed station and mobile unit, both equipped with the same $24-\mathrm{h}$ automatic analyzers. All data were logged and transferred by a continuous data collection and analysis system in a data quality control centre. The concentration of nitrogen oxides was analyzed by chemiluminescent monitors (Model API 200 A, precision $0.5 \%$ of the reading, detecting limit 0.4 $\mathrm{ppb}$, linearity error $1 \%$, response time $<60$ ). Wind speed and direction were measured using LASTEM sensor at yard level (wind speed opto-electric sensor: resolution $0.1 \mathrm{~m} / \mathrm{s}$, wind direction potenziometric sensor) and OPSIS/Jill sensor at roof level (vertical and horizontal wind speed: resolution $0.01 \mathrm{~m} / \mathrm{s}$, speed error limit $+/-1.5 \%$, direction error limit $+/-2^{\circ}$ ). Others meteorological factors such as temperature, pressure, relative humidity and solar radiation at both monitoring sites were continuously investigated. Ambient air temperature and humidity were measured respectively by a thermometer and a hygrometer. All these analytical instruments were calibrated with standard gases in laboratory. Furthermore, automatic counting of total traffic vehicles per 30 minutes was carried out by the communication agency of Suzhou.

\section{Results and discussion}

According to the prevailing meteorological situation, wind direction was southwest, between $160^{\circ}$ and $240^{\circ}$ (Fig.2), so both monitoring sites A and B were windward to the street.

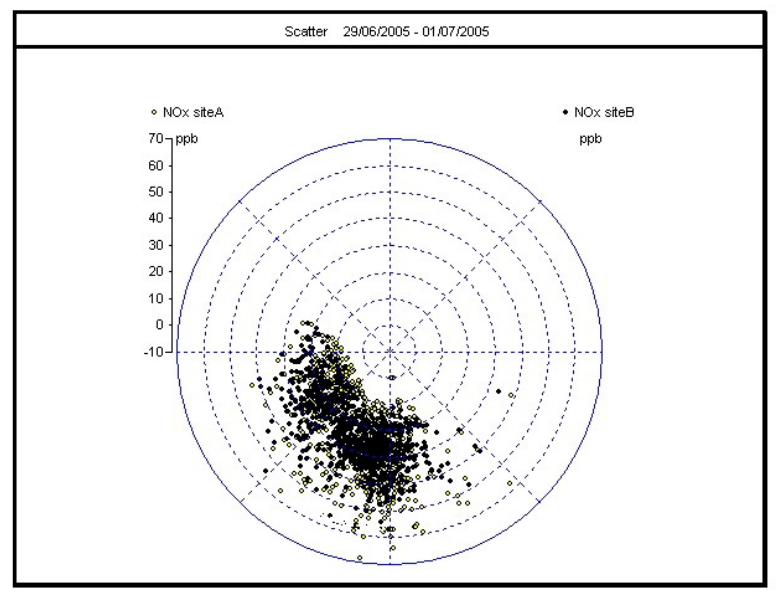

Figure 2: $\mathrm{NO}_{\mathrm{x}}$ concentration relative to wind direction during the measurement period on a $360^{\circ}$ basis $\left(0^{\circ}\right.$ indicates North).

The meteorological values measured are listed in table 1. 
Table 1.

\begin{tabular}{|lccccccc|}
\hline Date & $\mathrm{T}\left[{ }^{\mathrm{o}} \mathrm{C}\right]$ & & Wind Direction & $\begin{array}{c}\text { Wind } \\
{[\mathrm{m} / \mathrm{s}]}\end{array}$ & Speed & $\begin{array}{c}\text { Vertical } \\
\text { WS }[\mathrm{m} / \mathrm{s}]\end{array}$ \\
\hline & Site A & $\begin{array}{c}\text { Site } \\
\mathrm{B}\end{array}$ & Site A & $\begin{array}{c}\text { Site } \\
\mathrm{B}\end{array}$ & Site A & Site B & Site A \\
\hline $29 / 06$ & 26 & 29.2 & 201.9 & $\begin{array}{c}167 . \\
7\end{array}$ & 2.6 & 0.7 & -1.6 \\
$30 / 06$ & 26.8 & 30.1 & 194.2 & $\begin{array}{c}170 . \\
4\end{array}$ & 3.1 & 0.9 & -1.9 \\
$01 / 07$ & 28.9 & 32 & 219 & $\begin{array}{c}160 . \\
3\end{array}$ & 3.5 & 1 & -2.9 \\
\hline
\end{tabular}

Accordingly, the physical system's geometry, material properties and flow conditions were defined and the fluid domain is represented in figure 3.

The daily average concentrations of $\mathrm{NO}_{\mathrm{x}}$ and $\mathrm{NO}_{2}$ measured at ground level (site B) were higher than at roof level (site A), while NO concentration at the ground was lower than at roof level [8]. To investigate the pollutant vertical gradient, vertical wind speed was measured by a precise sensor: as a case, five minutes average data were collected in a selected whole day together with $\mathrm{NO}_{\mathrm{x}}$ concentration values (Fig.4).

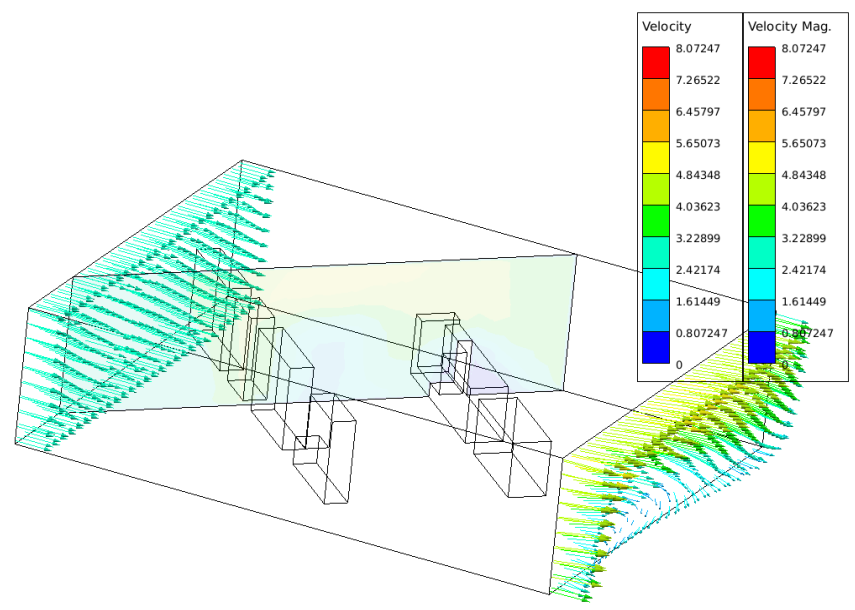

Figure 3: Representation of the fluid domain with the indication of inlet/outlet boundaries forming a $45^{\circ}$ angle with the plane normal to the street axis.

The negative vertical wind speed value measured here means there is a wind component coming from the top, and vice versa. When the vertical wind speed is 
less than $3 \mathrm{~m} / \mathrm{s}$ (from 3:30 to 7:35 and from 17:40 to 23:55) $\mathrm{NO}_{\mathrm{x}}$ values at ground level and roof level are quite similar. When the vertical wind speed is greater than $3 \mathrm{~m} / \mathrm{s}$ (from 8:10 to 17:35) $\mathrm{NO}_{\mathrm{x}}$ values at ground level are higher than at roof level.

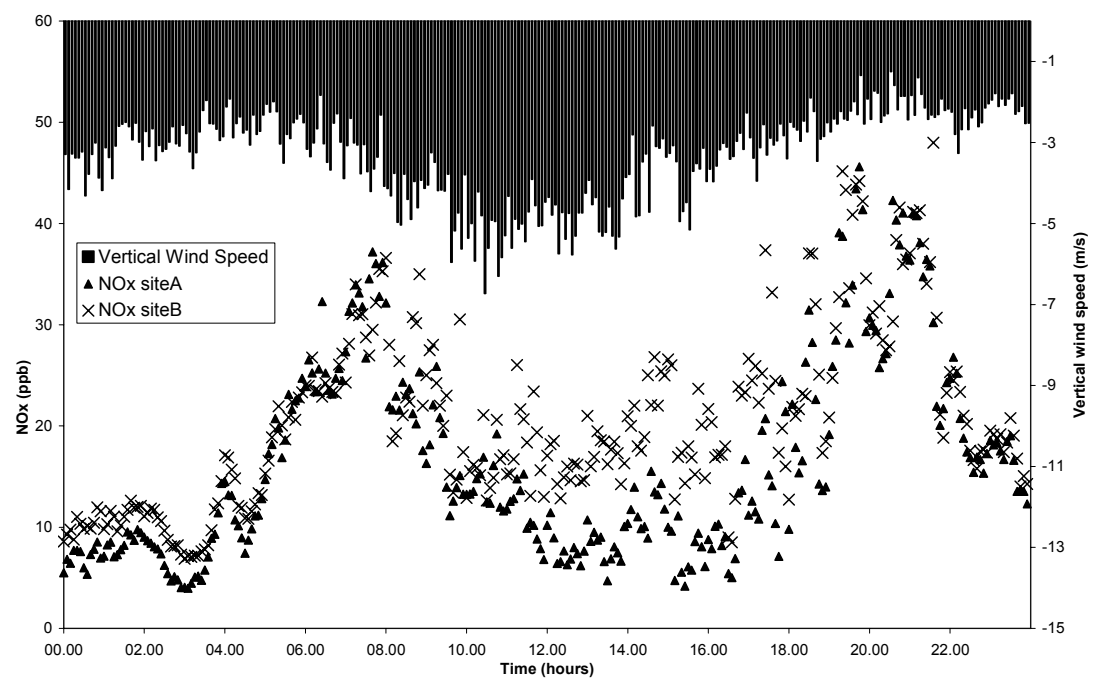

Figure 4: Vertical distribution of $\mathrm{NO}_{\mathrm{x}}$ at sites $\mathrm{A}$ and $\mathrm{B}$ (left axis) with vertical wind speed (right axis).

This is probably due to the up to down mass transfer together with the pollutant entrapment into the enclosed yard. There is nevertheless an evident correspondence of $\mathrm{NO}_{\mathrm{X}}$ peak values. All that indicates how the vertical wind speed strongly affects pollutant concentration, the more evidently the more one goes vertically away from the source.

Obviously, horizontal wind direction also affects the distribution of pollutants dominating the emission source at receptor site. Since most of $\mathrm{NO}_{\mathrm{x}}$ is in form of primary pollution, directly emitted from traffic exhausts, the emission source type can be more clearly investigated. During the measurement period of this work, wind direction was mainly from $160^{\circ}$ to $290^{\circ}$ (Fig. 2). Thus, both sites A and B were downwind to Sanxiang road, and the pollutants there measured came mainly from vehicle emissions. When the wind direction was close to $180^{\circ}, \mathrm{NO}_{\mathrm{x}}$ concentrations at both sites got the highest values, since both monitoring sites were just at the northward side of the traffic road.

Modelling of the fluid domain allows for the clear identification of both the entrapment zone into the yard and the up to down mass transfer. The figure 5 shows three section of the fluid domain perpendicular to the traffic street and forming a $45^{\circ}$ with the prevailing wind direction. The case of wind speed greater than $3 \mathrm{~m} / \mathrm{s}$ is showed there in order to better understand the ground and roof NOx trends measured. 


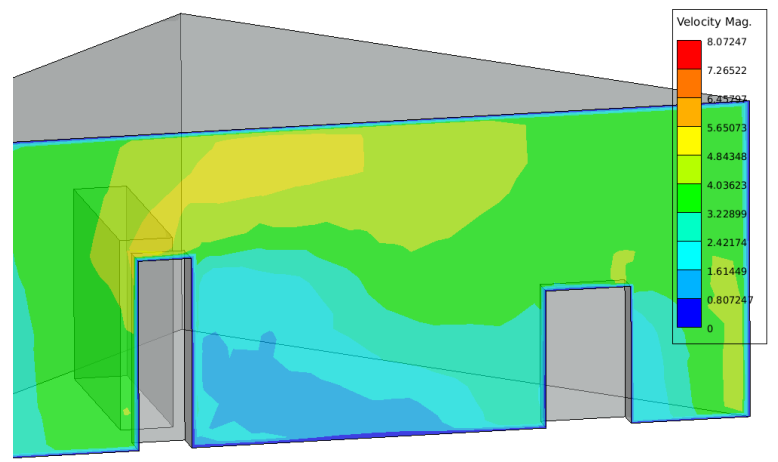

(a)

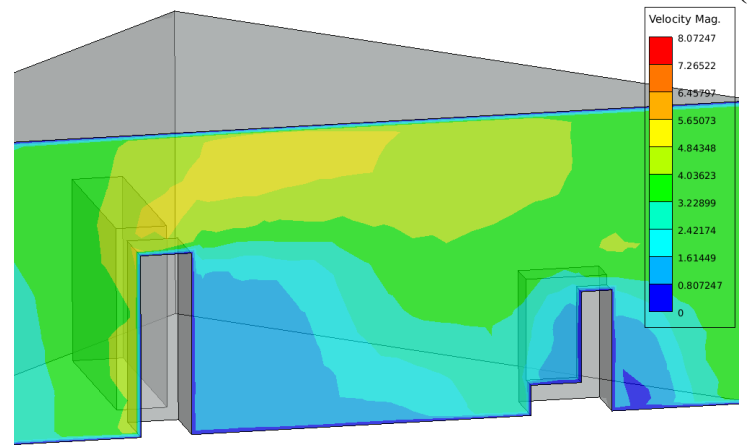

(b)

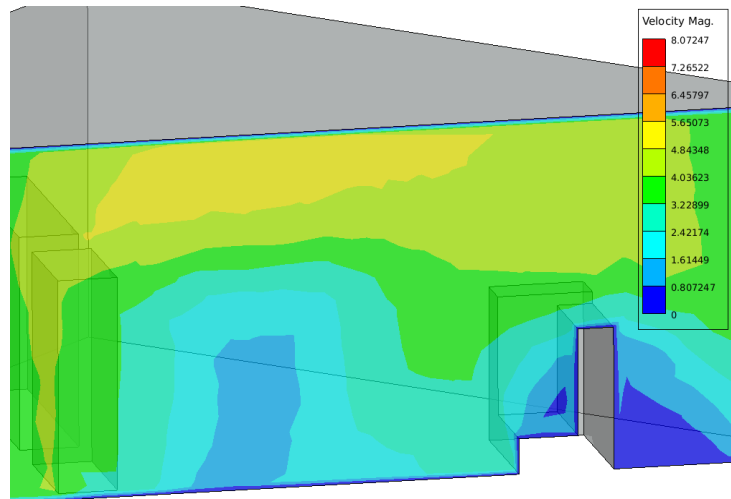

(c)

Figure 5: Wind flow isosurfaces along three sections of the fluid domain modelling. Fig. 5-a indicates the section containing the site A and fig. $5-b / c$ the site $B$. 


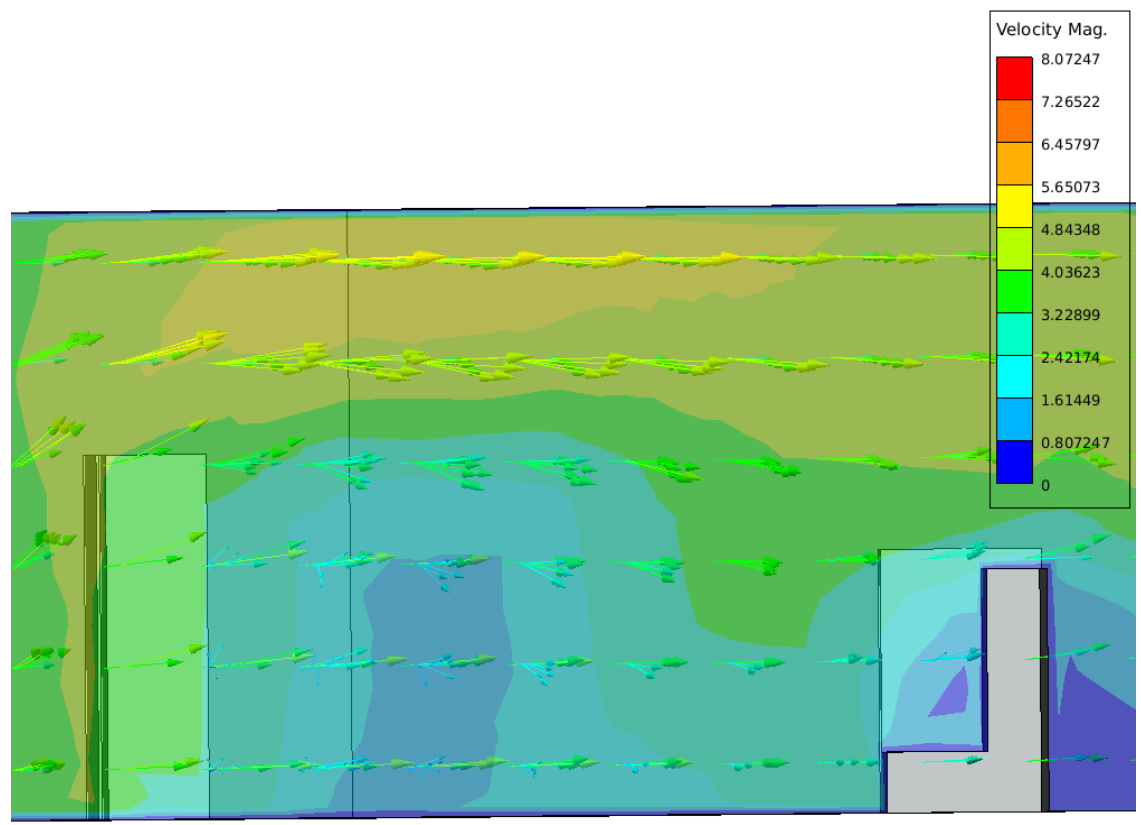

Figure 6: Velocity vectors modelled into the street-canyon.

By comparing table 1 and figure 5, it can be seen that the results modelled by CFD fit well with the field measurements. The wind velocity modelled at site B, inside the yard, ranges from $0 \mathrm{~m} / \mathrm{s}$ to $1 \mathrm{~m} / \mathrm{s}$ (fig.5-c), as well as wind direction modelled at site A, at the top of the building (fig. 5 -a), range from 2.5 to $3.5 \mathrm{~m} / \mathrm{s}$. The highest concentration measured at site $\mathrm{B}$ relative to site $\mathrm{A}$ is particularly evident in figure 6 , showing the velocity vectors based on the K- $\varepsilon$ turbulence model along the section perpendicular to the street and surrounding the two measurement points.

The vertical component of the wind vector inside the street-canyon is always down-ward causing the impact of polluted air masses from the street to be more significant upon the site B than the site A. This is particularly evident in figure 7 showing the detail of the velocity vector along two sections of the building, one perpendicular (fig.7-a) the other parallel (fig.7-b) to the street. It is clearly shown the negative vertical component of the velocity measured at site A. Therefore, the strong decrease of the horizontal component of velocity vector at site $\mathrm{B}$ is identified.

\section{Conclusions}

The air quality dataset obtained in this work by field monitoring, representative of a Chinese street canyon, has been used to simulate the traffic-related pollutant distribution by means of Computational Fluid Dynamic (CFD) tools. 


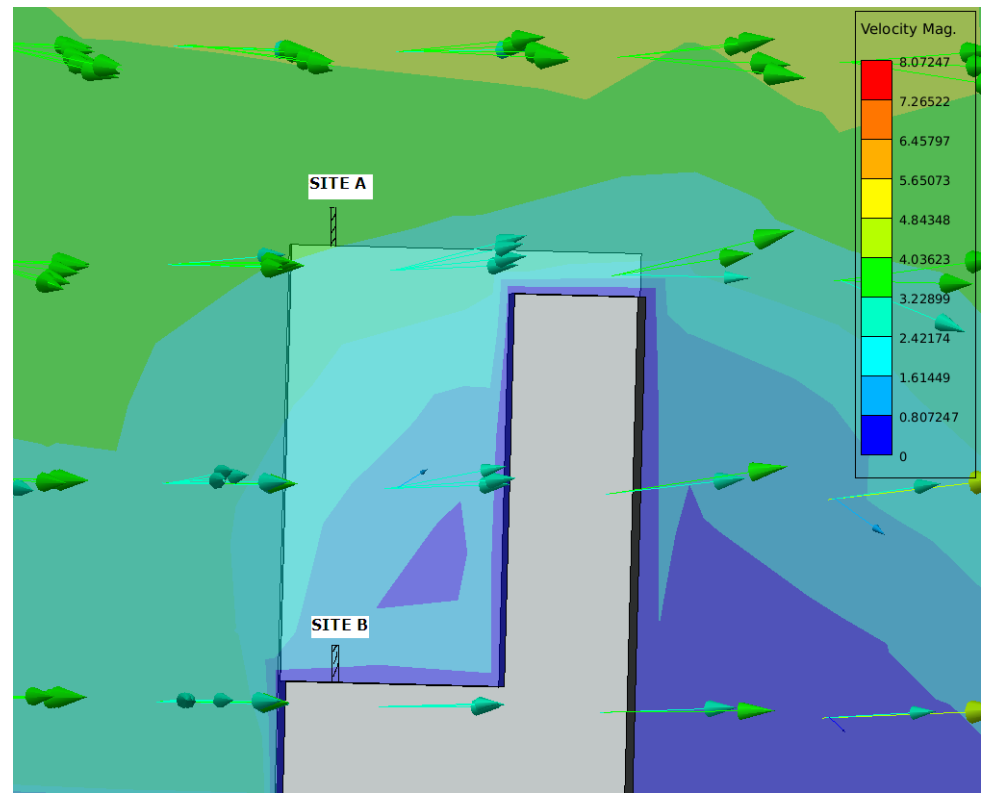

(a)

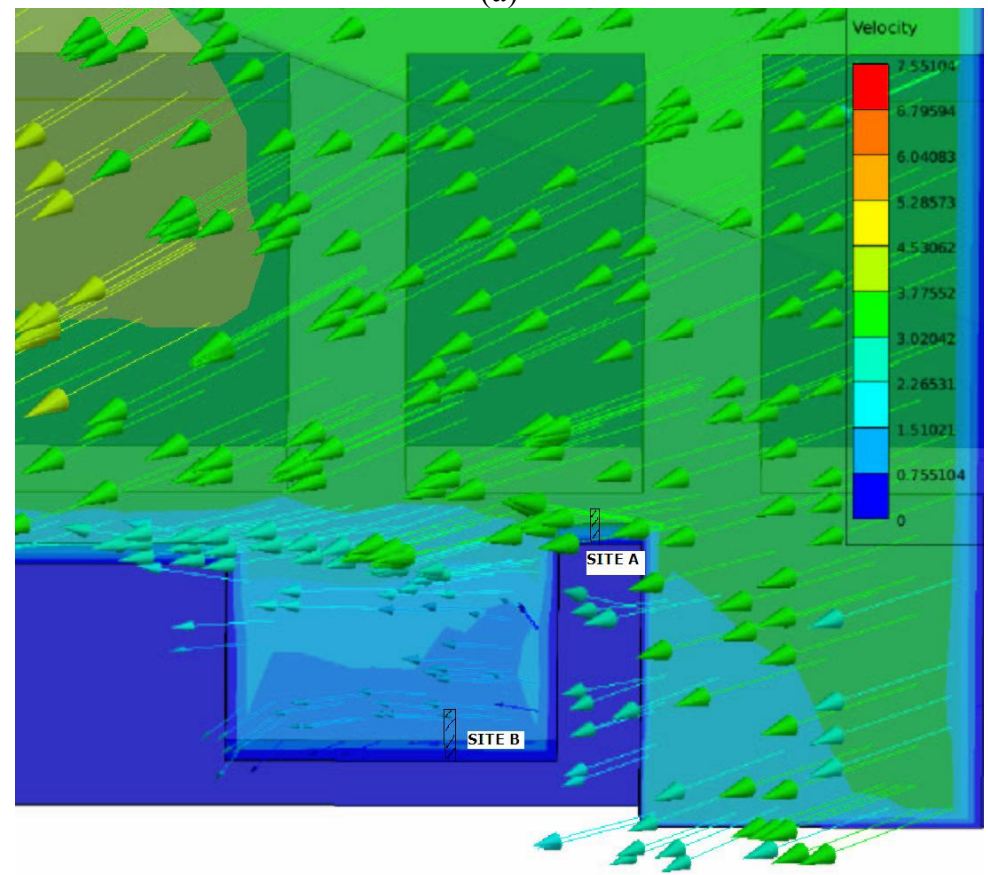

(b)

Figure 7: Velocity vector and isosurface of wind speed modelled in two sections of the fluid domain containing the two measurement points, $\mathrm{A}$ and $\mathrm{B}$. 
The results have been analysed to better understand the values of gaseous pollutants, meteorological parameters and traffic flows measured by means of automatic analyzers along the same street-canyon at two different heights. It has been found that the model correctly describes the vortex recirculation pattern around the building geometry studied and it's very useful in assessing the microscale pollution trends.

\section{References}

[1] Scaperdas, A., Colvile, R.N., 1999. Assessing the representativeness of monitoring data from an urban intersection site in central London, UK. Atmospheric Environment 33, 661-674.

[2] Vardoulakis, S., Fisher, B., Pericleous, K., Gonzalez-Flesca, N, 2003. Modelling air quality in street canyons: a review. Atmospheric Environment 37, 155-182.

[3] Kukkonen, J., Valkonen, E., Walden, J., Koskentalo, T., Aarnio, P., Karppinen, A., Berkowicz, R., Kartastenpaa, R., 2001. A measurement campaign in a street canyon in Helsinki and comparison of results with predictions of the OSPM model. Atmospheric Environment 35, 231-243.

[4] Pavageau, M., Schcatzmann, M., 1999. Wind tunnel measurements of concentration fluctuations in an urban street canyon. Atmospheric Environment 33, 3961-3971.

[5] Zhou H, Sperling D,. Traffic emission pollution sampling and analysis on urban streets with high-rising buildings. Transportation research part D6, 2001: 269-181.

[6] Xie, S., Zhang, Y., Qi, L., Tang, X., 2003. Spatial distribution of trafficrelated pollutant concentrations in street canyons. Atmospheric Environment 37, 3213-3224.

[7] Tsai, M.Y., Chen, K.S., 2004. Measurements and three-dimensional modeling of air pollutant dispersion in an Urban Street Canyon. Atmospheric Environment 38, 5911-5924.

[8] Costabile, F., Wang, F., Hong, W., Liu, F., and Allegrini, I., 2006. Spatial Distribution of Traffic Air Pollution and Evaluation of Transport Vehicle Emission Dispersion in Ambient Air in Urban Areas. JSME International journal, Series B, Vol.49, No.1, pp.27-34. (in press). 